\title{
Convulsion on Table in an American Society of Anesthesiologists Grade I Pregnant Patient Posted for Emergency Cesarean Section: Anesthesia Management
}

\author{
${ }^{1}$ Anjana Wajekar, ${ }^{2}$ Manisha Taware, ${ }^{3}$ Uma Kamat
}

\begin{abstract}
Convulsions occurring on the operating table in any patient, especially a pregnant patient, can be a nightmare. Initial management with regard to airway, breathing, and anticonvulsants remains the same. The differential diagnosis includes eclampsia, hypoglycemia, peripartum cerebrovascular thrombosis, subarachnoid hemorrhage, infection, intracranial tumor, head injury, idiopathic epilepsy, vasculitis, amniotic fluid embolism, etc. Magnetic resonance imaging of the brain of our patient revealed posterior reversible encephalopathy syndrome, a neuroradiological diagnosis. Management is supportive with anticonvulsants, cerebral decongestants, and treating the underlying cause including blood pressure control and early cesarean section. There is a small risk of permanent neurological damage or death.
\end{abstract}

Keywords: Cesarean section, Convulsions, Posterior reversible encephalopathy syndrome.

Abbreviations: Amniotic fluid embolism - AFE; Posterior reversible encephalopathy syndrome-PRES; American Society of Anesthesiologists - ASA; G2P1L1 - Gravida 2, para 1, live birth 1

How to cite this article: Wajekar A, Taware M, Kamat U. Convulsion on Table in an American Society of Anesthesiologists Grade I Pregnant Patient Posted for Emergency Cesarean Section: Anesthesia Management. Res Inno Anaesth 2016;1(1): 25-27.

\section{Source of support: Nil}

Conflict of interest: None

\section{INTRODUCTION}

Peripartum convulsion can significantly increase both maternal and fetal morbidity and mortality. ${ }^{1}$ Any convulsion occurring in a pregnant patient after 20 weeks is always assumed to be eclampsia and treated likewise. Immediate termination of pregnancy is advised only in case of recurrent seizures in labor. ${ }^{1}$ But every seizure increases the risk of abruption and maternal aspiration and fetal acidosis, hypoxia, intracranial bleed, and death. ${ }^{1}$ Other differential diagnosis of peripartum seizure also needs to be ruled out, but initial management of

\footnotetext{
${ }^{1,2}$ Assistant Professor, ${ }^{3}$ Postgraduate Student

${ }^{1-3}$ Department of Anaesthesia, Seth GSMC and KEM Hospital Mumbai, Maharashtra, India
}

Corresponding Author: Anjana Wajekar, Assistant Professor Department of Anaesthesia, Seth GSMC and KEM Hospital Mumbai, Maharashtra, India, e-mail: anjanawajekar@gmail.com convulsion remains airway, breathing and circulation, seizure control, and fetal health.

We present a case of management of preoperative on-table convulsions in an American Society of Anesthesiologists (ASA) grade I patient posted for emergency cesarean section.

\section{CASE REPORT}

A 22-year-old, gravida 2, para 1, live birth 1 (G2P1L1) patient at 37 weeks of gestation, with history of one previous cesarean section, was taken for emergency cesarean section for nonreassuring fetal Doppler. Her systemic examination and all her routine blood investigations including complete blood count, renal and liver function tests, and coagulation profile were normal.

In the operating room, her pulse was $56 / \mathrm{min}$, blood pressure $178 / 108 \mathrm{~mm} \mathrm{Hg}$, and room air saturation $100 \%$. Left uterine displacement was maintained. Ringer's lactate was started. Before the patient could be positioned for spinal anesthesia, she developed left-hand focal convulsion with secondary generalization which lasted for 2-3 minutes, followed by unconsciousness. Midazolam $1 \mathrm{mg}$ was injected intravenously. The patient was immediately intubated following rapid sequence induction with intravenous thiopentone $250 \mathrm{mg}$ and succinylcholine $100 \mathrm{mg}$. Antiaspiration prophylaxis with ranitidine $50 \mathrm{mg}$ and ondansetron $4 \mathrm{mg}$ was given. Anesthesia was maintained with isoflurane 0.8 minimum alveolar concentration in oxygen:nitrous oxide mixture $(50 \%)$ and intermittent vecuronium bolus. Her blood sugar level was $81 \mathrm{mg} / \mathrm{dl}$. Labetalol $20 \mathrm{mg}$ was given for persistent hypertension intraoperatively. The baby was delivered in 10 minutes with an APGAR (Appearance, Pulse, Grimace, Activity, Respiration) score of 9 at 1 minute. Thereafter, fentanyl $100 \mu \mathrm{g}$ and oxytocin $20 \mathrm{U}$ in slow drip were given. The uterus was well contracted and hemostasis achieved. Levetiracetam $500 \mathrm{mg}$ was administered intravenously. The patient was extubated on table after return of spontaneous ventilation and full consciousness.

Patient was shifted to the intensive care unit. Hypertension persisted postoperatively, which was treated with bolus dose of labetalol $10 \mathrm{mg}$ and later shifted to oral alpha-methyldopa $500 \mathrm{mg}$ and nifedipine $10 \mathrm{mg}$. The patient had six more episodes of generalized tonic-clonic 

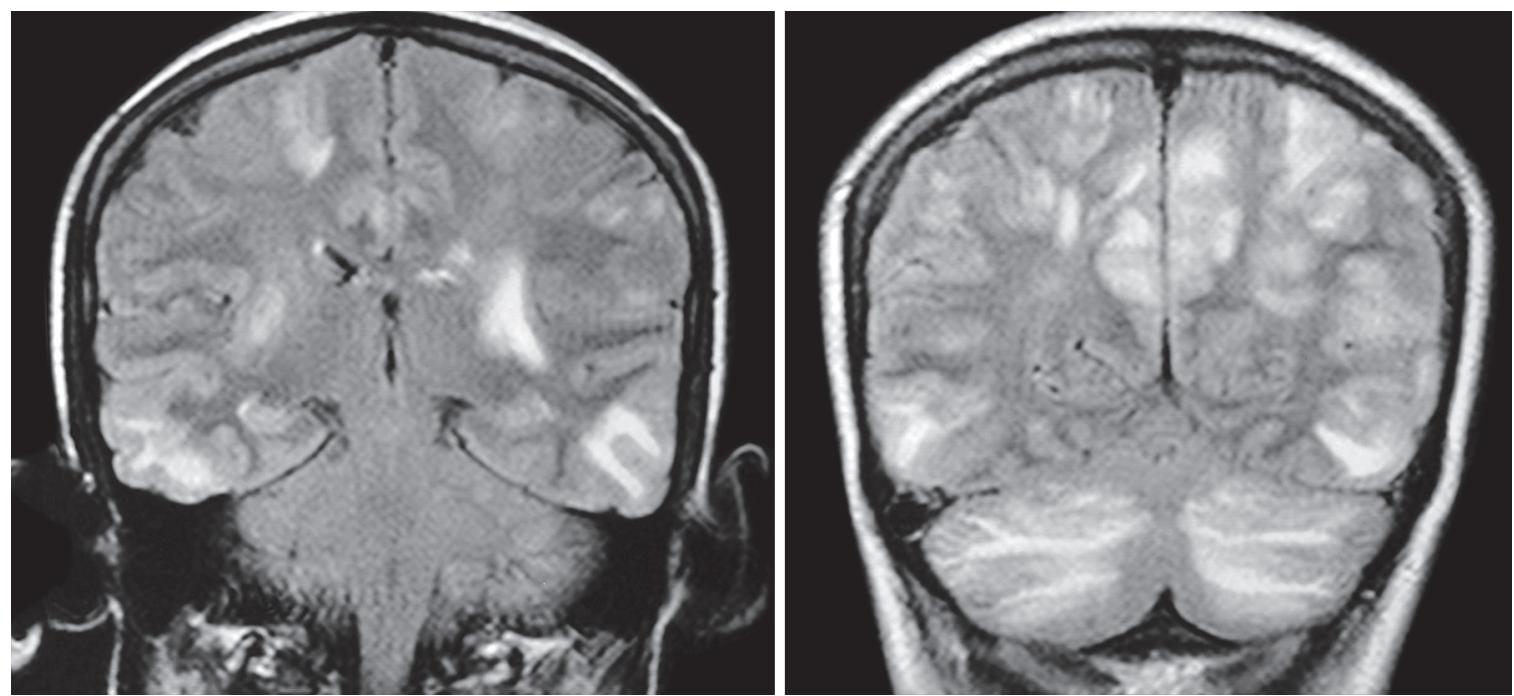

Fig. 1: Postoperative magnetic resonance imaging brain scan

convulsions within the next 24 hours. Phenytoin $100 \mathrm{mg}$, mannitol, and dexamethasone were added. Postoperative proteinuria was negative. All other postoperative investigations remained normal. Fundoscopy revealed no papilledema. Postoperative magnetic resonance imaging brain scan showed bilateral hyperdensities in cerebellar hemispheres, basal ganglia, occipital, parietal, temporal, and frontal lobes consistent with posterior reversible encephalopathy syndrome (PRES) (Fig. 1). She was discharged on day 15 with antihypertensive and anticonvulsant medications.

\section{DISCUSSION}

The differential diagnosis of peripartum seizures includes eclampsia, hypoglycemia, peripartum cerebrovascular thrombosis, subarachnoid hemorrhage, infection (meningitis or encephalitis), intracranial tumor, head injury, idiopathic epilepsy, vasculitis, amniotic fluid embolism, idiopathic, psychogenic, etc. ${ }^{2}$ Our patient had no past history of epilepsy, head trauma, or fever. Her white cell counts and sugar levels were normal. Amniotic fluid embolism is generally associated with cardiopulmonary collapse and coagulopathy. ${ }^{2}$ Magnetic resonance imaging of the brain was diagnostic and showed signs consistent with PRES.

Rapid control of maternal hypertension with labetalol is important. Rapid institution of general anesthesia with endotracheal intubation was the best course of action, since the patient was taken up in view of nonreassuring fetal Doppler, and further delay was unadvisable. It is preferable to avoid magnesium sulfate intraoperatively due to prolongation of nondepolarizing blockade and uterine atony. ${ }^{3,4}$ Neonatal exposure to antiepileptic drugs preoperatively may adversely affect their neuronal development. Forcelli et $\mathrm{al}^{5}$ found that synaptic maturation was absent in rats exposed to a single dose of phenobarbital, phenytoin, or lamotrigine but not levetiracetam. Studies have found that in utero exposure of phenytoin or levetiracetam has a very low risk of congenital malformations $(<3 \%)$, and it is dose dependent. ${ }^{6,7}$ In view of potential fetal complications, presence of pediatrician during delivery is essential as fetal resuscitation may be required.

Posterior reversible encephalopathy syndrome is a neuroradiological diagnosis, first described by Hinchey et $a .^{8}$ It is recognized by a variety of names like reversible posterior cerebral edema syndrome, reversible posterior leukoencephalopathy syndrome, and reversible occipital parietal encephalopathy. It is characterized by vague symptoms like headache, altered sensorium, visual disturbances, vomiting, and seizures especially with secondary generalization. ${ }^{8}$ Although acute hypertension is not a symptom of PRES, it is found in $67 \%$ of the patients with PRES. ${ }^{8}$ It can be associated with a wide array of diseases like preeclampsia, HELLP (hemolysis, elevated liver enzymes, low platelet count) syndrome, encephalopathy, renal diseases, cerebral infections, sepsis, immunosuppressants, etc. ${ }^{8,9}$ The pathophysiology is generally intracranial vasogenic edema secondary to cerebral hyperperfusion. ${ }^{8,9}$ Magnetic resonance imaging brain with T2 fluid attenuated inversion recovery (FLAIR) sequence is diagnostic and showed a typical holohemispheric watershed pattern in our patient. Management is supportive with anticonvulsants, cerebral decongestants, and treating the underlying cause including blood pressure control and early cesarean section. ${ }^{9}$ There is a small risk of permanent neurological damage or death. ${ }^{8}$

\section{CONCLUSION}

Basic management of on-table convulsion with regard to airway, breathing and circulation, and anticonvulsants 
should always be kept in mind and management best titrated to maternal and fetal outcome should be done.

\section{REFERENCES}

1. Pandey R, Garg R, Darlong V, Punj J, Khanna P. Recurrent seizures in pregnancy-epilepsy or eclampsia: a diagnostic dilemma? A case report. AANA J 2011 Oct;79(5):388-390.

2. Sprung J, Rakic M, Patel S. Amniotic fluid embolism during epidural anesthesia for cesarean section. Acta Anaesthesiol Belg 1991;42(4):225-231.

3. Habe K, Kawasaki T, Sata T. [A case of prolongation of rocuronium neuromuscular blockade in a pregnant patient receiving magnesium]. Masui 2014 Jul;63(7):817-819.

4. Siddik-Ahmad RI, Garabedian MJ, Jelks A. Inadequate uterine contractions increase risk for uterine atony at cesarean delivery. Obstet Gynecol 2014;123 Suppl:80S.
5. Forcelli PA, Janssen MJ, Vicini S, Gale K. Neonatal exposure to antiepileptic drugs disrupts striatal synaptic development. Ann Neurol 2012 Sep;72(3):363-372.

6. Harden CL. Pregnancy and epilepsy. Continuum (Minneap Minn) 2014 Feb;20(1 Neurology of Pregnancy):60-79.

7. Hernández-Díaz S, Smith CR, Shen A, Mittendorf R, Hauser WA, Yerby M, Holmes LB; North American AED Pregnancy Registry; North American AED Pregnancy Registry. Comparative safety of antiepileptic drugs during pregnancy. Neurology 2012 May22;78(21):1692-1699.

8. Postma IR, Slager S, Kremer HPH, de Groot JC, Zeeman GG. Long-term consequences of the posterior reversible encephalopathy syndrome in eclampsia and preeclampsia: a review of the obstetric and nonobstetric literature. Obstet Gynecol Surv 2014 May;69(5):287-300.

9. Fukami T, Asakura H, Takeshita T. Reversible posterior leukoencephalopathy syndrome due to eclampsia in a woman with a twin pregnancy produced with donated oocytes. J Nippon Med Sch 2013;80(3):230-233. 